\title{
Thirty years of in-patient consultation-liaison psychiatry at Guy's
}

\author{
Ben Lucas and Harry Doyle
}

\begin{abstract}
In order to inform planning decisions, we aim to show how an in-patient consultation-liaison service has changed in 30 years. A year's referral of 175 inpatients was compared with surveys carried out in the same hospltal 20 and 30 years previously. Neurosciences continue to refer the greatest percentage of its patients while general medicine produces the greatest demands on the service. There has been a large increase in substance misuse referrals, although other diagnostic groups have similar referral rates. Liaison service planners should be aware of the unmel demand for psychiatric services of the general hosplital in-patient population.
\end{abstract}

The importance of consultation-liaison psychiatry has recently been highlighted in the Tomlinson Report, which emphasises the high level of psychiatric morbidity found in general hospital in-patient populations (Tomlinson, 1992). This report relies on the evidence of psychiatric morbidity surveys of hospital populations by, for example, Maguire et al (1974) and Bridges \& Goldberg (1984). Maguire showed that $23 \%$ of acute medical in-patients had a psychiatric disorder and this figure represents the size of the potential demand for a liaison service. Gater \& Goldberg (1991) have shown that the general hospital doctor refers as much as a third of all patients newly referred to a mental health service. If Tomlinson's recommendations are acted upon, liaison psychiatric services will be subject to review and services will need to be organised to provide for this large source of psychiatric morbidity.

In planning a consultation-liaison service, there is a need for information about the likely demand. At the coarse level, this means considering how many psychiatrist-hours are needed, based on the total number of patients referred. At the finer level, it means knowing who is making the most referrals, as the non-psychiatric speciality so identified might prove a fruitful area for close cooperation with non-psychiatric staff. Another concern is to identify groups of patients who are underreferred, so that remedial action can be taken; for example, are patients from certain ethnic groups less likely to be referred for an opinion?

The first general hospital to admit what were then called lunatics was Guy's in 1728 (Mayou, 1989) and one of the earliest and deliberately planned consultation-liaison services was established there by StaffordClark in the 1950s (Fleminger \& Mallett, 1962) and re-surveyed in the late 1960s (Anstee, 1972). Consultation-liaison services in other centres have been usefully reviewed elsewhere (Levitan \& Kornfeld, 1981; Lipowski, 1986). In this study, reports on the consultation-liaison service at Guy's are used to answer the above questions and the services in 1962, 1972 and 1992 are compared in order to illuminate trends. Out-patient consultation-liaison referrals were not reported 30 years ago and unfortunately out-patient referral details have not been systematically collected today, so the study is restricted to medical and surgical inpatients.

\section{The study}

All the in-patient liaison records from June 1992 to May 1993 were examined. These records are questionnaires completed by the psychiatrist to whom the referral is passed. They are kept for clinical purposes, including audit, so it is not surprising that some were incomplete in some way. Questionnaires were not completed on the patients who had self-harmed and who were admitted to the observation ward in Casualty. Most of these patients were not subsequently admitted and were dealt with by one of 
two dedicated psychiatric nurses who would refer to a duty psychiatrist (not part of the liaison service) if necessary. It should be emphasised that many patients who deliberately self-harm and who never become in-patients are thus excluded from this in-patient survey.

\section{Findings}

\section{Organisation of the service}

The consultation-liaison service is divided into consultant-based teams, each of which has one or two juniors attached. Two teams take referrals from general and specialist medical services excluding neurology but including the elderly, one team takes referral from surgical specialities and neurology and one team takes oncology referrals. Regular meetings including ward round attendance were held with neurologists and oncologists but not other firms. Referrals were mainly dealt with by juniors, supervised by consultants, although all oncology referrals were seen by the senior lecturer. Nearly all patients were seen on the day of referral.

Those patients with deliberate self-harm not requiring medical admission were not dealt with by the consultation-liaison service but rather by the general emergency psychiatric services, including a psychiatric nurse and duty psychiatrist.

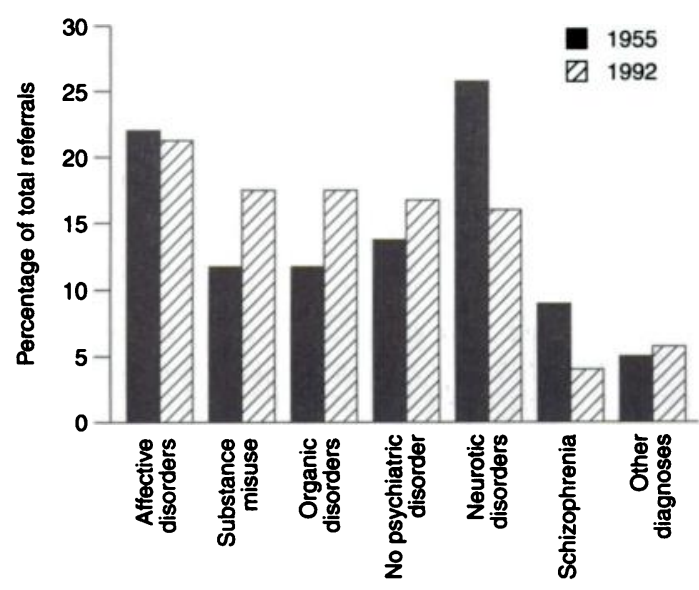

Fig. 1. Comparison of diagnoses between 1955 and 1992. Total referrals: 1955-60: 300 (100\%); 1992-93: 148 (100\%).

\section{In-patient referrals to psychiatric services}

One hundred and seventy-five referrals were made of which 27 records were missing. Over the same period there were 36252 consultant episodes (day patients are excluded) in the general hospital, giving a referral rate of $0.48 \%$. This figure rises to $0.71 \%$ if the 83 Accident and Emergency observation ward admissions are added. These 83 patients are not referred to further except when explicitly mentioned in the comment section.

General medicine referred most patients, 78 or $53 \%$ of valid referrals. General surgery referred 20 patients or $14 \%$, neurosciences 18 or $12 \%$ and other specialities still less $(3 \%$ missing). However, neurosciences referred most when number of patients seen by that department is considered. Thus 18 out of 494 or $3.6 \%$ of neurosciences patients are referred for a psychiatric opinion. This is followed by general medicine at $1.7 \%$ and oncology at $0.70 \%$. Orthopaedics and general surgery have lower referral rates of $0.46 \%$ and $0.39 \%$ respectively, and obstetrics and gynaecology has the lowest rate of all departments of $0.04 \%$.

Overall, 22 or $19 \%$ of patients referred were from ethnic minorities. However, different specialities had widely differing ethnicity referral patterns; 16 or $25 \%$ of medical patients referred were non-white, whereas only two or $9 \%$ of surgical and orthopaedic patients combined were from minority ethnic groups.

Figure 1 shows the main diagnoses of patients referred both in 1962 and in 1992. Other diagnoses include learning disability, but also deliberate self-harm with no psychiatric diagnosis. The figure for substance misuse in 1955-60 (but not 1992) includes personality disorders as the diagnoses are not reported separately.

\section{Comment}

\section{Organisation of the service}

Only two consultants ran the service 30 years ago and saw most of the patients themselves with a very much smaller workload of referrals (60 per year v. 148 today) (Fleminger et al, 1962). The advantages of a smaller service, allowing it to be consultant-led and facilitating data collection, may be offset by the lack of opportunities to train juniors and to develop closer 'outreach' liaision with particular other services. 


\section{In-patient referrals to psychiatric services}

Compared with the psychiatric morbidity detailed in earlier studies (Maguire et al. 1974) few patients overall $(0.5 \%)$ are referred for a psychiatric opinion. This has been noted elsewhere in the UK (Lloyd, 1980; Brown \& Cooper, 1987). There are several possible explanations for this low referral rate; wanting to avoid stigmatising their patients, therapeutic nihilism, restricting their workload, not recognising psychiatric disorder may all contribute to the reluctance (Steinberg et al, 1980). Negative perceptions of the psychiatric service as slow to respond or otherwise unhelpful may also deter. Good clinical practice by other psychiatric services may also reduce the need for consultationliaison services. While many of those psychiatrically ill might most appropriately be looked after by GPs after discharge or by the non-psychiatric staff in the hospital, it does suggest that there is considerable underreferral with resulting loss of therapeutic opportunities. Psychiatric resources need to be provided to address the unmet needs of general hospital in-patients. However, as mental health trusts split off from general health service providing units, referral rates might be expected to decline to a still lower level, unless purchasers can be made aware of the psychiatric needs of hospital in-patients.

While general medicine produces the greatest workload for a consultation-liaison service, the greatest percentage of total inpatients referred is from neurosciences. This finding is consistent with both earlier surveys of 20 (Anstee, 1972) and 30 years ago (Fleminger et al, 1962) when 'specialist medicine' (which included dermatology, venereology and neurologyl produced the greatest number. This suggests it is an appropriate target for the development of a 'special relationship' with closer cooperation between neuroclinician and psychiatrist. This type of liaison activity is already carried out by two branches of the liaison service at Guy's. The low level of referral from obstetrics and gynaecology may reflect the fact that their admissions are very common, very brief and often without pathology.

Although numbers are small, the underreferral by surgical specialities of ethnic minority patients suggests that liaison psychiatry is not exceptional compared to other mental health services in terms of accessibility (Fernando, 1988; Donovan, 1986).
Compared with 30 years ago overall rates of referral have remained the same at $0.7 \%$, but the rates are lower now if those taking overdoses and only on the observation ward are excluded. Compared with 20 years ago, when deliberate self-harm referrals were also reported separately (Anstee, 1972). there has been a decline in referrals other than deliberate self-harm from $0.7 \%$ to $0.5 \%$. Stafford-Clark's optimism (1963) about the development of consultation-liaison psychiatry has not been borne out. This lack of an increase is disappointing, but a different picture might be expected in other centres, given the historically early integration of psychiatric and general services that occurred at Guy's. Out-patient details are not available but clearly out-patient work is a very important part of liaison psychiatry and likely to become increasingly so, given the expansion in general hospital out-patient and day services. Future reports of psychiatric liaison services should certainly include out-patient activity, although in sectorised, communitybased services these data may be expensive to collect.

Depressive disorders remain the most common disorder at just over one-fifth of cases. (Observation ward admissions are excluded). The most striking difference is the increase in substance misuse. This was not even classified separately from personality disorder in the earlier study, which together made up only $12 \%$ of cases, while in this study $15 \%$ of diagnoses made were of substance misuse alone. This still represents a small fraction of the substance misuse morbidity in general hospital in-patients, up to $30 \%$ of whom have alcohol as a contributory factor to their admission. Effective management of substance misuse thus forms a major part of the work of a psychiatric liaison service.

\section{Acknowledgements}

The authors wish to thank Professor Watson and Drs Rosen, Master and Ramirez for allowing their patients to be included in the study and for their helpful comments on the text.

\section{References}

ANSTEE, B. H. (1972) The pattern of psychiatric referrals in a general hospital. British Journal of Psychiatry. 120. $631-634$. 
Bridges, K. W. \& GoldBerg, D. P. (1984) Psychiatric illness in inpatients with neurological disorders: patients' views on discussion of emotional problems with neurologists. British Medical Journal, 289, 656-658.

BRown, A. \& COOPER, A. F. (1987) The impact of a liaison psychiatry service on patterns of referral in a general hospital. British Journal of Psychiatry, 160, 83-87.

Donovan, J. (1986) Black people's health: a different approach. In Health, Race and Ethnicity (eds $T$. Rathwell and D. Philips). London: Croom Helm.

Fernando, S. (1988) Race and Culture in Psychiatry. pp 127-193. London: Tavistock.

FLEMINGER, J. J. \& MALLETT, B. L. (1962) Psychiatric referrals from medical and surgical wards. Journal of Menta Science, 108, 183-190.

GATER. R. \& GOLDBERG, D. (1991) Pathways to psychiatric care in South Manchester. British Journal of Psychiatry. 169. 90-96.

LEVITAN, S. J. \& KoRNFELD, D. S. (1981) Clinical and cost benefits of liaison psychiatry. American Journal of Psychiatry. 138, 790-793.

LPOWSKI, Z. J. (1986) Consultation-liaison psychiatry: the first half-century. General Hospital Psychiatry. 8. 305-315.

LLOYD, G. G. (1980) Liaison psychiatry from a British perspective. General Hospital Psychiatry, 2, 46-51.

MAguire, G. P., Julier, D. L., HAWTON, K. E., et al (1974) Psychiatric referral and morbidity on two general medical wards. British Medical Journal, 1, 268-270.
MAYOU, R. (1989) The history of general hospital psychiatry. British Joumal of Psychiatry. 155. 764-776.

SteinBerG, H., TOREM, M. \& SARAVAY, S. M. (1980) An analysis of physician resistance to psychiatric consultations. Archives of General Psychiatry. 37. 1007-1012.

STAFFORD-ClARK, D. (1963) Psychiatry Today. 2nd edition. pp 248-249. London: Penguin.

Tomunson, B. (1992) Report of the Inquiry into London's Health Service. Medical Education and Research. Paragraph 64. HMSO.

*Ben Lucas, Clinical Research Fellow in Community Psychiatry, North West London Mental Health Trust formerly Registrar, Guy's Hospital, London); and Harry Doyle, Consultant Psychiatrist, Northwick Park Hospital, Harrow, Middlesex HAl 3UJ (formerly Senior Registrar, Guy's Hospital, London)

*Correspondence 